\title{
EXPERIMENTAL ANALYSIS OF A HEAT PUMP ASSISTED RECUPERATIVE AIR DEHUMIDIFIER
}

C. A. B. Pereira
R. H. Pereira
R. P. Marques

J. A. R. Parise

Pontifícia Universidade Católica

do Rio de Janeiro

Department of Mechanical Engineering

22453-900 Rio de Janeiro BRAZIL

tel: 5521529 9536; fax: 55212949148

parise@mec.puc-rio.br

J.R. Sodré

Pontifícia Universidade Católica

de Minas Gerais

Department of Mechanical Engineering 30535-610 Belo Horizonte BRAZIL ricardo@pucminas.br

\section{ABSTRACT}

This paper describes the experimental analysis of a heat pump assisted recuperative air dehumidifier. The system consisted of an air-to-air vapor compression heat pump, coupled to the air ducting. Dehumidification was generated by reduction of the air temperature through the evaporator below the dew point, and thus promoting the condensation of the water vapor. Moist air was then warmed up in the condenser, resulting in a lowtemperature low-humidity air stream. Low energy consumption values are achieved in such systems as the latent heat of the water vapor acts as the heat pump own heat source. Occasionally, the compressor heat is also recoverable. The innovative feature of the present analysis was the introduction of an air-to-air plate recuperator, to further promote dehumidification, yet at the expense of greater compressor energy consumption. An experimental apparatus was constructed to perform comparative tests of the dehumidifier operating with and without the recuperator. A closed air circuit was employed, with the air mass flow rate as the controlling parameter of the experiment. Tests were also carried out with an open circuit.

\section{INTRODUCTION}

Owing to their capacity of delivering more energy as heat than they in fact consume as input work, many applications have been found for vapor compression heat pumps. In this respect, drying and dehumidification processes have been among the major areas of application for heat pumps. Traditional methods of drying involve the direct combustion of fossil fuel together with controlled ventilation. Such methods present efficiencies that hardly exceed $20 \%$, depleting (expensive) primary energy whose only effect is to produce low grade heat. In an early study, Hodgett (1976) estimated that approximately 150 million GJ were consumed annually in drying processes in the British industry, which accounted, in 1975 figures, for 6\% of the total industrial energy consumption (iron and steel and electricity generation industries excluded). Food, paper, timber and pharmaceutical industries are amongst those that would most benefit from the application of heat pump dryers.

Figure 1 shows a typical arrangement for a heat pump assisted dehumidifier (Reay, 1979; Reay and Macmichael, 1979). Humid air from the chamber (that contains the material to be dried) flows across the heat pump evaporator, which cools the air below the dew-point. Sensible and latent heat is thus removed from the air stream. And water vapor, contained in the air, is condensed and drained out. The heat removed from the humid air stream, in the evaporator, is then up-graded by the heat pump and released in the condenser. The relative humidity of the air is then reduced. The resulting dry air is directed to the drying chamber to remove moisture of the material to be dried. One major advantage of heat assisted dehumidifiers is the possibility of providing dry air at a desired temperature.

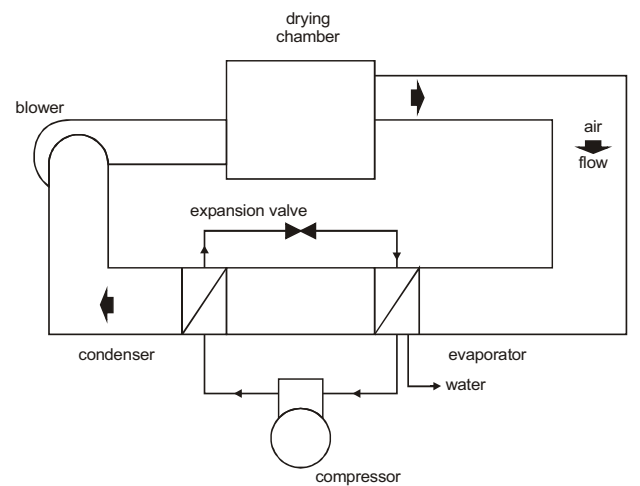

Figure 1. Schematics of a heat pump assisted dehumidifier.

Figure 2 depicts three configurations of heat pump dehumidifiers. Figure 2a shows the standard configuration, as illustrated in Figure 1. In the arrangement of Figure $2 b$, a cross-flow air-to-air plate heat exchanger is placed in the air stream. Humid air, from the drying chamber, is directed towards the heat exchanger (a latent and sensible heat recuperator) where it is cooled by the cold stream from the evaporator. In comparison with the con- 
figuration of Figure 2a, further dehumidification is expected to occur, due to the pre-cooling of the humid air stream from the drying chamber, before it enters the evaporator. The resulting warmer air is directed to the condenser. This configuration, known as thermodynamic geared heat pump, has been previously studied by Iacovides (1982) and Cartwright (1987). The internal heat exchange has the effect of lowering the evaporating temperature, cooling further the incoming air, and increasing the condensing temperature (Cartwright, 1987). The overall effect, due to the greater heat pump temperature lift, is an increase in the compressor energy consumption. Finally, Figure 2c displays an open circuit dehumidifier with recuperator. Its major objective is to dehumidify external air, reducing the humidity ratio. In such an arrangement dehumidification occurs at both the evaporator and recuperator.
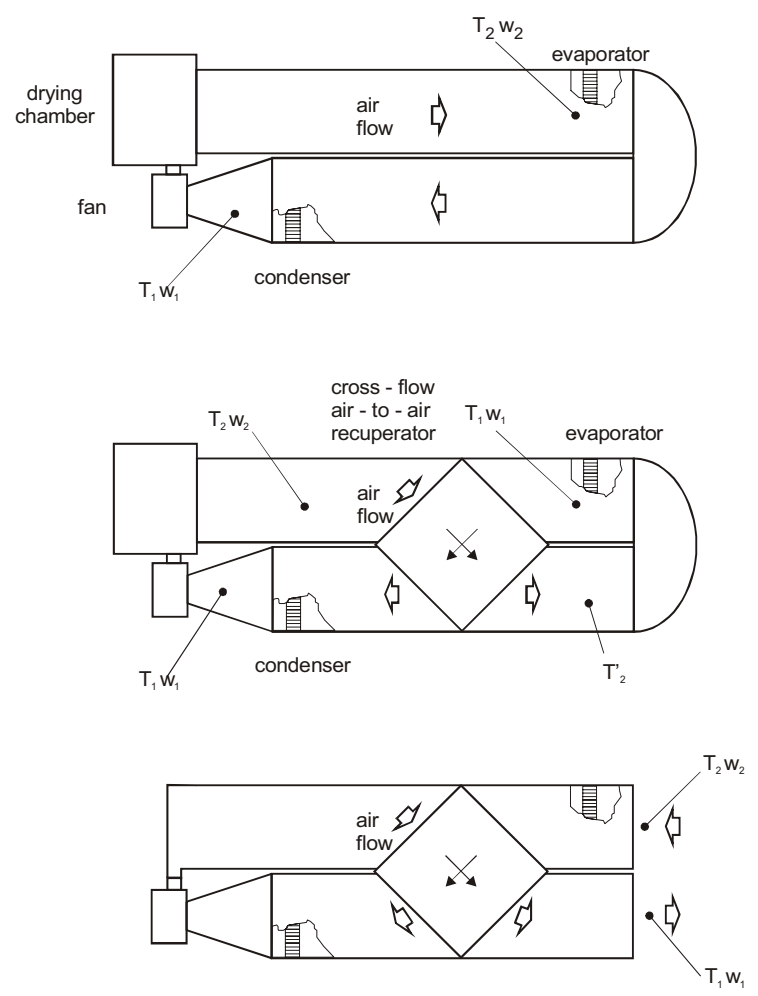

Figure 2. Diagram of the configurations of the dehumidifiers studied.

The basic principles of heat pump assisted dehumidification can be found in Reay (1979) and Reay and MacMichael (1979). Lazzarin (1994, 1995) carried out a review on industrial heat pumps, featuring drying applications. It was pointed out that the amount of heat absorbed by a wet material in a dryer varies from 5 to $10 \%$ of the energy supplied, and therefore, $90-95 \%$ of this energy may be recovered by means of a heat pump assisted dryer, leading to substantial energy savings. The addition of heat pumps to drying processes can be made in several different ways. Five drying/dehumidifi-cation systems, including three with heat pumps, have been compared theoretically by Zilla et al. (1982). Although requiring careful matching, a closed cycle dryer has shown to be the most advantageous one.
Chen at al. (1980) carried out comparative experimental studies between solar-only and solar assisted heat pumps for lumber drying. The heat pump assisted system proved to be more efficient. Test of a R-114 heat pump dehumidification system was carried out by Tai et al. (1982a, 1982b). The heat pump coefficient of performance was plotted against the evaporating to condensing temperature lift, for several air bypass ratios and air velocities. Coefficients of performance in excess of 3 were attained with the experimental apparatus. Hogan et al. (1983) presented the development and testing of a lowtemperature heat pump grain dryer. The design technique and features were discussed in the paper. A comparison between the heat pump assisted dryer and a conventional electrical resistance heating is presented. Further experimental work is described by Toal et al. (1988a, 1988b) in which several different types of cycles and dryers are compared. These authors concluded that the best performance, both in terms of drying time and energy saving, is achieved with pure recirculation of air, a heat pump dehumidifier and supplementary resistance heating. Results also suggested that air entering the drying chamber at a higher temperature, albeit moist, is more effective in removing moisture than drier and colder air. An interesting assessment of heat pump dehumidifiers was carried out by Carrington and Liu (1995), who used a psychrometric calorimeter for a better control of the air state. Bannister et al. (1995) studied the influence of an evaporator economizer and liquid subcooler on the operating parameters and performance of a heat pump dehumidifier. They found out that the drying capacity and efficiency were most significant at low relative humidity, but further increases were limited by thermal effectiveness of the economizer. More recently, Bannister et al. (1998) studied a heat pump dehumidifier kiln. Performance was assessed during commercial-scale operation.

Theoretical analyses of heat pump assisted dryers can also be found in the literature. For instance, Cartwright (1987) describes the modeling of the heat pump assisted dryer, with an air-to-air heat exchanger included. Baines and Carrington (1988) conducted a simulation analysis where different configurations and the effects of modifications to basic design were studied. A second law analysis of heat pump driers was also carried out Carrington and Baines (1988). Almeida et al. (1990) developed a simulation model to predict the performance of a heat pump assisted air-dehumidifying system. Their study devised a conventional dehumidifying system where the air flow was pre-heated by an air-to-air heat pump. Ambient air was employed as the heat source for the heat pump. Since the heat pump was used only to provide warm air to the drying chamber, no latent heat of the humid air was recovered. Even for this simpler configuration, the study has shown that a considerable energy reduction can be attained with the use of a heat pump. Pendyala et al. (1990) presented a mathematical model for an integrated heat pump assisted dryer. The model was developed considering both heat transfer and mass transfer processes that take place in such systems. Heat exchangers were modeled by establishing energy conservation equations for differential heat exchangers lengths considering the various zones on the air and refrigerant sides. The compressor was 
modeled by a polytropic compression equation. It was found that there exists an optimum combination, for the values of evaporator approach velocity and compressor suction superheat, that minimizes the dryer specific energy consumption. Pendyala et al. (1990) also compared their simulation results with data from heat pump assisted dryers running on both R11 and R12. Satisfactory agreement between simulation and experimental data was observed. It was also found that, although the system COP value of 2.5 was lower for the system operating with R12 than with R11 (COP of 3.5), the dryer specific energy consumption (SEC, defined as the energy supplied for unit weight of the moisture removed) was better for operation with R12. This may be justified by the use of an electrical heater to maintain the drying temperature while the system was running on R11. It should be stressed that, in this case, different system configurations and different design details have to be taken into account when comparisons are made. Jolly et al. (1990) developed a numerical model for the simulation of a heat pump coupled to a conventional hot air continuous drying system. The dryer modeled consisted of a vapor compression heat pump upgrading heat from a cross-flow dryer. The model considered the detailed heat and mass transfer phenomena taking place in each component of the system. Results of this simulation were presented in a second paper (Jia et al., 1990). The authors investigated several key aspects of the system, and concluded that the evaporator air by-pass ratio is not as critical as pointed out by earlier works. This appear to be in conflict with the results reported by Pendyala et al. (1990), that concluded that the evaporator approach air velocity plays a decisive role on the dryer performance. A comprehensive model of the dynamics of a dehumidifier wood drying kiln was developed by Sun and Carrington (1999). Their model solves the fundamental balance equations for the whole system and was applied for typical operating conditions and kiln controls.

In a two-fold article Adapa et al. (2002a, 2002b) have made a thorough study of a heat pump assisted drying of specialty crops. A specific moisture extraction rate (SMER) between 0,5 and $1,02 \mathrm{~kg} \cdot \mathrm{kW}^{-1} \cdot \mathrm{h}^{-1}$ was achieved when chopped alfalfa was dried in a cabinet dryer in batches. Their simulation model and experimental work pointed to a preference of continuous bed drying over batch drying. Braun et al. (2002) examined the feasibility of an air heat pump cycle for tumbler clothes dryers. They claimed that significant efficiency improvements over conventional dryers may be achieved.

New applications of heat-pumps in drying processes were investigated by Strommen and Kramer (1994). By combining fluidized bed driers and heat pumps these authors obtained controlled drying temperatures in the $20^{\circ}$ $-50^{\circ} \mathrm{C}$ range which offers the possibility of freeze-drying at ambient pressure and drying above $0^{\circ} \mathrm{C}$ in the same plant. Later, Prasertsan and Saen-Saby (1998) have shown the economic feasibility of the heat pump dryer for some agricultural materials.

Simulation models of heat pump dryer components were developed by Prasertsan et al (1996, 1997a, 1997b). Heat pump dryer character-istics of four configurations (two open and two closed systems) were thoroughly investigated. Prasertan et al. (1996, 1997a, 1997b) took the specific moisture extraction rate (SMER), the moisture extraction rate (MER) and the coefficient of performance (COP) as criteria to assess the heat pump dryer performance. Computer simulation predictions agreed with experimental results within an acceptable error tolerance. An economic viability and a technological assessment (advantages and disadvantages) of heat pump dryers over existing heating methods (i.e. direct electrical heating and diesel burners) also appeared in the literature (Meyer and Greyvenstein, (1992). Finally, two review articles should be mentioned. Pratersan and Saen-saby (1998) stressed the need for further investigation on HPD configurations with respect to all operating variables and further research on working fluids. In a very recent review article Chua et al. (2002) outlined advantages and disadvantages of HPD, new hybrid HPD technologies and further opportunities on research of versatile heat pump designs.

An experimental study of a heat pump dryer, whose innovative feature is the use of an air-to-air recuperator, is carried out. The trade-off between dehumidification rate and energy consumption is the aim of the present work.

\section{EXPERIMENTAL APPARATUS}

An experimental apparatus was built to study the effect of the installation of the air-to-air recuperator in a closed circuit heat pump assisted drier. The prototype was devised to allow for the easy establishment of the three different configurations studied (Figures 2a, 2b and 2c) without the need for significant changes in the air ducting. Figure 3 shows, schematically, the experimental apparatus. Main components are: the compressor (cp), evaporator (ev), condenser (cd), air blower (bw), drying chamber (mc). The U-shaped air duct had a square opening that could be filled by a duct separator (A), to form the ungeared system, or by the air-to-air cross flow heat exchanger (B), to promote air preheating at the condenser inlet. Therefore, as shown in Figure 3, two air flows were made possible:

a) Either the air stream leaves the drying chamber (mc), crosses the condenser (cd), from point 8 to point 9 , and then crosses the evaporator (ev), from 10 to 11 , towards the air blower (bw); or,

b) The air stream, coming from the drying chamber (mc), flows to the air-to-air heat exchanger (recuperator), from 18 to 9 , and then to the evaporator (ev), 9 to 8 , and again flows through the recuperator, 8 to 10 , to the condenser (cd), 10 to 11 , and, finally, is directed to the blower. 


\section{CIÊNCIA/SCIENCE}

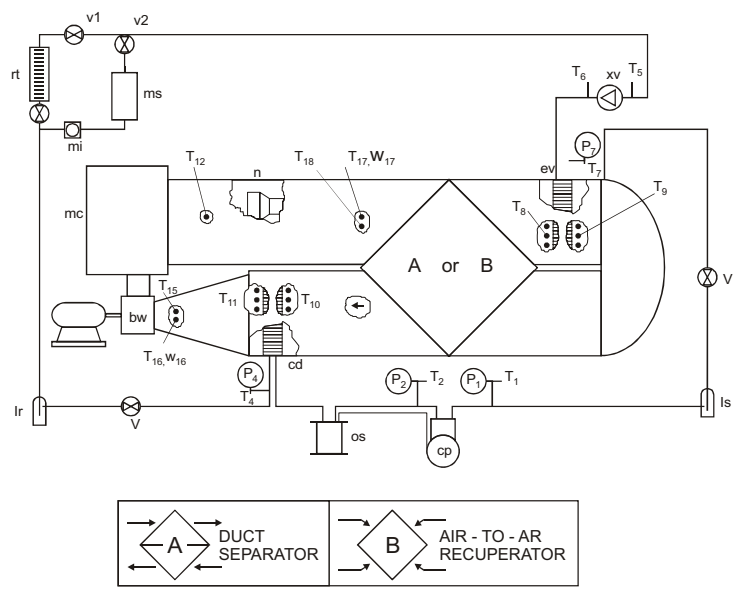

Figure 3. Test rig.

An open reciprocating single cylinder compressor, driven by an electric motor, was utilized. The compressor was rated at $0.5 \mathrm{~kW}$. An open type compressor was chosen in order to allow for a proper choice of shaft speed. The compressor-motor coupling was such that the compressor rotational speed was $620 \mathrm{rpm}$. Typical platefin-and-tube coils were used for the evaporator and the condenser. Geometry details are provided in Table 1. A thermostatic expansion valve was used, of 1.5 ton of refrigeration, and an orifice of $3.0 \mathrm{~mm}$ diameter. A separator tank was installed before the compressor to contain liquid particles of refrigerant, as a safety measure. Other components installed in the system included a drying filter, check valves, oil separator and a pressure regulator.

Table 1. Details of the condenser and evaporator.

\begin{tabular}{lcc}
\hline & CD & EV \\
\hline number of rows (transverse) & 12 & 9 \\
number of rows (longitudinal) & 4 & 3 \\
cross-sectional measures $(\mathrm{m})$ & $0.30 \mathrm{x}$ & $0.28 \mathrm{x}$ \\
& 0.31 & 0.24 \\
tube inner diameter $(\mathrm{mm})$ & 7.9 & 7.9 \\
tube outer diameter $(\mathrm{mm})$ & 12.5 & 12.5 \\
fin thermal conductivity & 0.228 & 0.228 \\
(W/m. $\left.{ }^{\circ} \mathrm{C}\right)$ & & \\
transverse tube pitch (mm) & 26 & 20 \\
longitudinal tube pitch $(\mathrm{mm})$ & 26 & 25 \\
fin spacing (mm) & 2 & 1 \\
fin thickness (mm) & 0.3 & 0.1 \\
\hline
\end{tabular}

The air was circulated by a centrifugal blower, driven by an electric motor. The air conduit had a cross section of $300 \times 300 \mathrm{~mm}$. The conduit had a device to vary the cross-flow section, obtaining air flow from 0.1 to 0.5 $\mathrm{kg} / \mathrm{s}$. The air passed through a drying chamber, which contained a metallic screen covered with cotton. To humidify the cotton, a tube placed at the top of the chamber conducted distilled water from an external reservoir. The air-air heat exchanger was built up with $0.5 \mathrm{~mm}$ aluminum plates. Forty-eight plates were used.

The flow rates of air and refrigerant were measured by a nozzle and a rotameter, respectively. Air temperatures were measured by copper-constantan thermocouples. Before each test, the system was kept working for about two hours, to reach steady state condition. At each test run, the cross section of the air conduit was varied, to obtain different air mass flow rates. Then, the readings of the instruments were recorded. The data recorded included temperature, pressure, flow rate and power consumption. All the required properties were evaluated from those parameters.

\section{RESULTS}

Figure 4 depicts the evaporator superheat against the air mass flow rate. In each case the evaporating temperature was kept fairly constant. It can be seen that, with the recuperator, the evaporator superheat remains fairly constant, at $5{ }^{\circ} \mathrm{C}$. Without the recuperator, it increases almost linearly with the air mass flow rate. Apparently, the heat exchanger smoothes out the variations on air outlet temperatures, at both condenser and evaporator, which would otherwise occur, if removed. With the recuperator, the evaporator temperatures tend to be more constant over the operating range of the air mass flow rate.

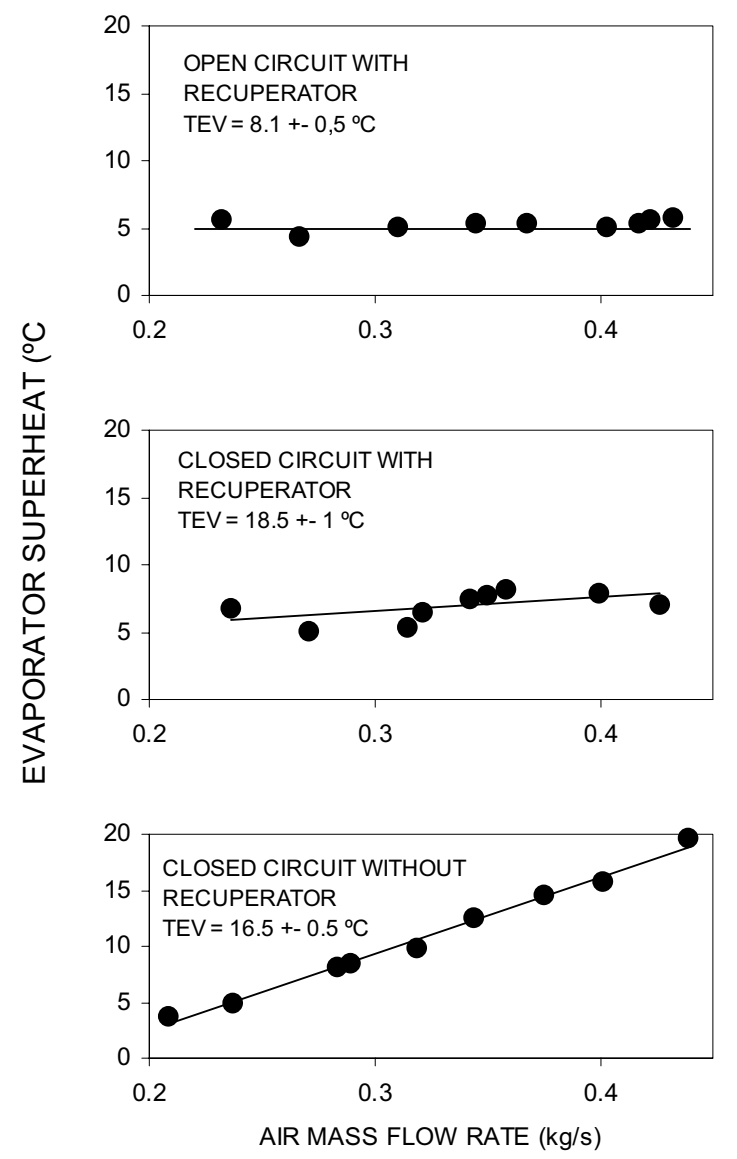

Figure 4. Evaporator superheat vs air mass flow rate.

With the recuperator, more heat can be transferred to the air in the heat source (condenser), since temperatures are lower at the condenser entrance. Without the recuperator, less heat is taken by the air stream, if the air mass flow rate increases. By contrast, temperatures at the heat source and heat sink outlets are greater if the recuperator is added to the equipment. This can be observed 


\section{CIÊNCIA/SCIENCE}

from Figure 5, where the condenser thermal power output is plotted against the air mass flow rate. Additional information on the recuperator thermal performance is shown in Figure 6. The recuperator effectiveness, which remained close to $30 \%$, explains why its presence contributes only marginally to the system performance.

Further, to assess system efficiency, two coefficients of performance were considered: the heating coefficient of performance, $\mathrm{COP}_{\mathrm{H}}$, which takes only into account the electrical power provided to the compressor and the global coefficient of performance, $\mathrm{COP}_{\mathrm{G}}$, which takes into consideration the power consumed by the blower. Figure 7 depicts these COP's, which showed to be insensitive to the air mass flow rate for all configurations.
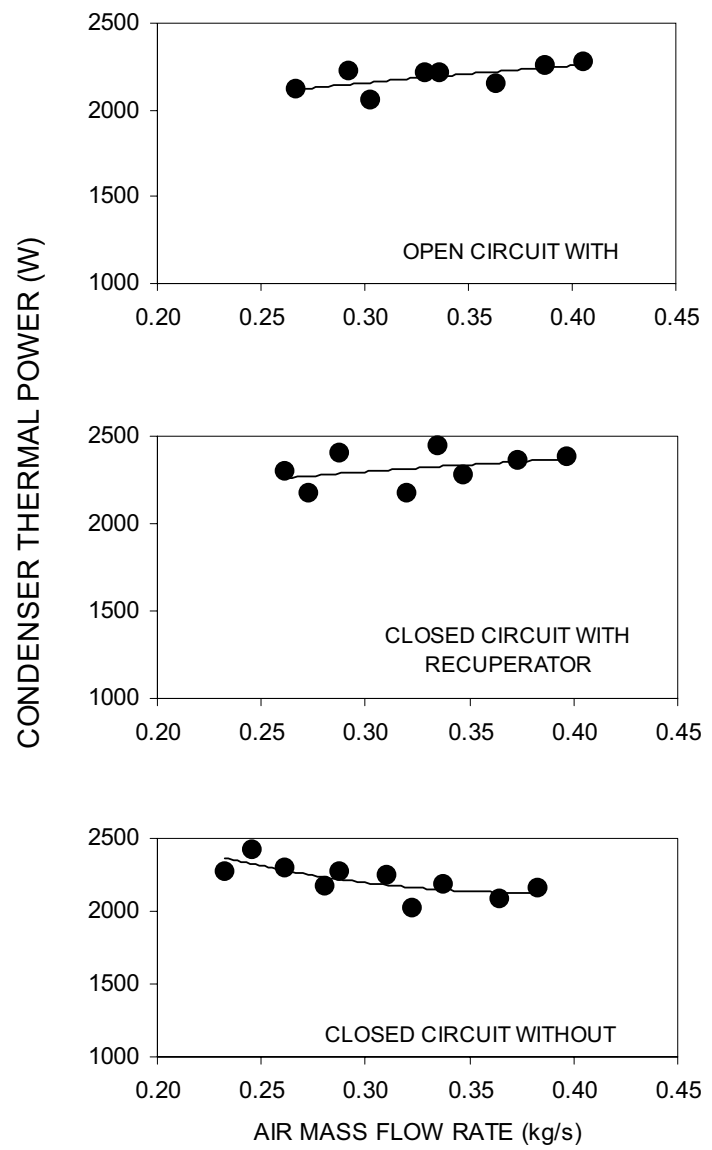

Figure 5. Condenser thermal power vs air mass flow rate.

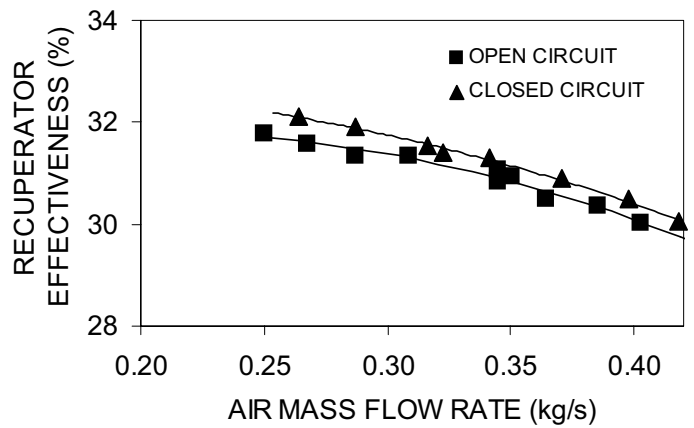

Figure 6. Recuperator effectiveness $v s$ air mass flow rate.
C. A. B. Pereira et al. Experimental Analysis of...

\section{CONCLUDING REMARKS}

Heat pump assisted air dehumidifiers can be an effective device for drying processes in the timber, food, paper and pharmaceutical industries. The additional compressor energy consumption required is counterbalanced by the energy savings if traditional (fossil fuel or electrical resistance) dryers were used instead. The introduction of an air-to-air plate recuperator, whose major advantage is to promote further dehumidification, increases, however marginally, the overall performance of the system. However, good behavior of industrial heat pump air dehumidifiers also depends on the machinery and equipment design.
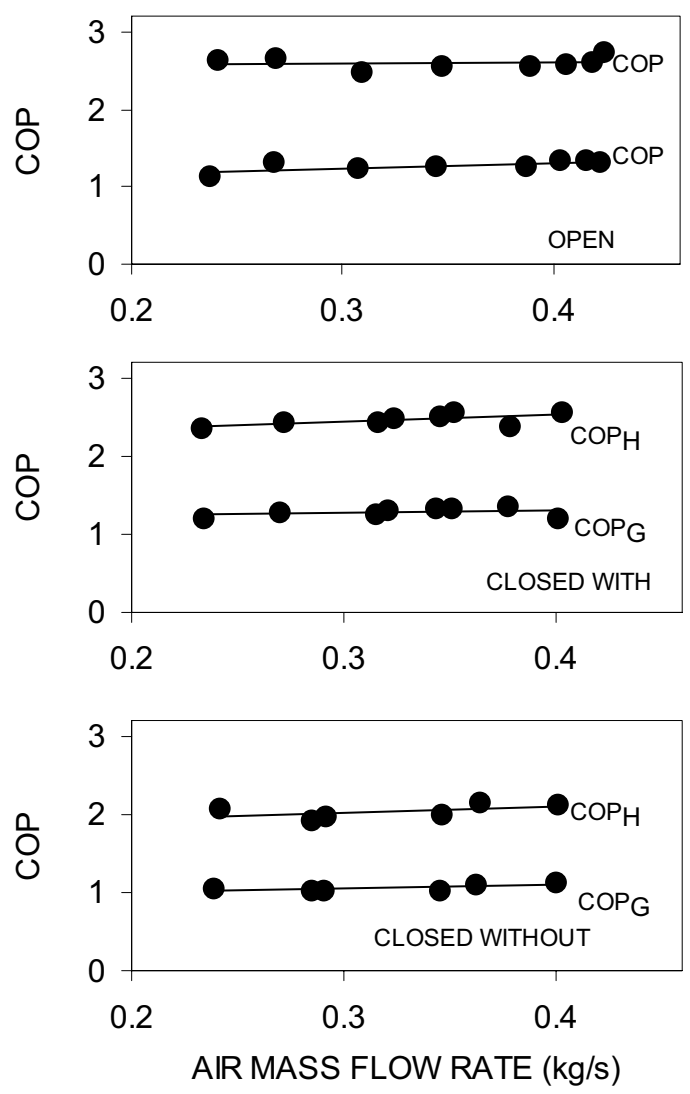

Figure 7. COP $v s$ air mass flow rate.

\section{ACKNOWLEDGEMENTS}

The authors would like to express his gratitude to CAPES, CNPq and FAPERJ for the financial support.

\section{REFERENCES}

Adapa P.K.; Schoenau G.J.; Sokhansanj S., 2002, Performance study of a heat pump dryer system for especialty crops - Part 1: Development of a simulation model, International Journal of Energy Research, 26(11), pp.1001-1019.

Adapa P.K.; Schoenau G.J.; Sokhansanj S., 2002, Performance study of a heat pump dryer system for especialty crops - Part 2: Model verification, International Journal of Energy Research, 26(11), pp. 1021-1033. 
Almeida. M.S.V.; Gouveia, M.C.; Zdebsky, S.R.; J.A.R. Parise, 1990, "Performance analysis of a heat pump assisted drying system", International Journal of Energy Research , 14(4), pp. 397-406.

Baines, P.G.; Carrington, C.G., 1988, Analysis of Rankine cycle heat pump driers, International Journal of Energy Research, 12(3), pp. 495-510.

Bannister, P.; Bansal, B.; Carrington, C.G.; Sun, Z.F., 1998, "Impact of kiln losses on a dehumidifier drier", International Journal of Energy Research,, 22(6), pp. 515-522.

Bannister, P.; Carrington, C.G.; Liu, Q., 1995, "Influence of Enhancing Features on Dehumidifier Performance Laboratory Measurements", International Journal of Energy Research, 15(5), pp. 397-406.

Braun J.E.; Bansal P.K.; Groll E.A., 2002, "Energy efficiency analysis of air cycle heat pump dryers", International Journal of Refrigeration, 25(7), pp. 954-965.

Carrington, C.G.; Baines, P.G., 1988, "Second law limits in convective heat pump driers", International Journal of Energy Research, 12(3), pp. 481-494.

Carrington, C.G.; Liu, Q., 1995, "Calorimeter Measurements of a Heat Pump Dehumidifier - Influence of Evaporator Air Flow", International Journal of Energy Research, 19(8), pp.649-658.

Cartwright, W.G., 1987, "Computer modelling of an energy-efficient drying plant", 4th Asean Energy Conference - Energy Technology, pp. 268-279.

Chen, P.Y.S.; Helmer, W.A.; Rosen, H.N., 1980, "Pilot plant studies of solar dehumidification lumber drying", 15th Intersociety of Energy Conversion Engineering Conference, Energy to the 21st century, Seattle, USA, pp. 23162323.

Chua, K.J.; Chou, S.K.; Ho, J.C.; Hawlader M.N.A., 2002, "Heat pump drying: Recent developments and future trends", Drying Technology, 20(8), pp. 1579-1610.

Hodgett, D.L., 1976, "Efficient drying using heat pumps", The Chemical Engineer, pp. 510-512.

Hogan, M.R.; Ayers, D.L.; Muller, Jr.; R.E., Foster, G.H.; Rall, E.C.; Doering, O.C., 1983, "Heat pump for lowtemperature grain drying", Transactions of the ASAE , pp. 1234-1238.

Iacovides, H., 1982, Heat pump application in the drying process, MSc Thesis, Deaprtment of Mechanical Engineering, UMIST, England.

Jia, X.; Jolly, P.; Clements, S., 1990, "Heat Pump Assisted Continous Drying. Part 2: Simulation Results", International Journal of Energy Research, 14(7), pp. 771-782.

Jolly, P., Jia, X.; Clements, S., 1990, "Heat Pump Assisted Continous Drying. Part 1: Simulation Model", International Journal of Energy Research, 14(7), pp. 757-770.

Lazzarin, R., 1994, "Heat Pumps in Industry - I. Equipment", Heat Recovery Systems \& CHP, 14(6), pp. 581-597.

Lazzarin, R., 1995, "Heat Pumps in Industry - II. Applications", Heat Recovery Systems \& CHP, 15(3), pp. 305317.

Meyer J.P.; Greyvenstein G.P., 1992, "The drying of grain with heat-pumps in South-Africa - A technoeconomic analysis", International Journal of Energy Research, 16 (1), 13-20.

Pendyala, V.R.; Devotta, S.; Patwardhan, V.S., 1990, "Heat-Pump-Assisted Dryer Part 1: Mathematical Model",
International Journal of Energy Research , 14(5), pp. 479492.

Pendyala, V.R; Devotta, S.; Patwardhan, V.S., 1990, "Heat-Pump-Assisted Dryer Part 2: Experimental Study", International Journal of Energy Research, 14(5), pp. 493507.

Prasertsan S.; Saen-saby P., 1998, "Heat pump dryers: Research and development needs and opportunities", Drying Technology, 16(1-2), pp. 251-270.

Prasertsan S.; Saen-saby P., 1998, "Heat pump drying of agricultural materials", Drying Technology, 16(1-2), pp. 235-250.

Prasertsan S.; Saen-saby P.; Ngamsritrakul P.; Prateepchaikul G., 1996, "Heat pump dryer.1 Simulation of the models", International Journal of Energy Research, 20 (12), pp. 1067-1079.

Prasertsan S.; Saen-saby P.; Ngamsritrakul P.; Prateepchaikul G., 1997, "Heat pump dryer. 2 Results of the simulation", International Journal of Energy Research, 21(1), pp. 1-20.

Prasertsan S.; Saen-saby P.; Ngamsritrakul P.; Prateepchaikul G., 1997, "Heat pump dryer. 3 Experimental verification of the simulation", International Journal of Energy Research, 21(8), pp. 707-722.

Reay, D.A. and Macmichael, D.B.A, 1979, Heat pumps: design and applications, Pergamon Press.

Reay, D.A., 1979, Industrial Energy Conservation, 2nd edition, Pergamon Press.

Strommen I.; Kramer K., 1994, "New applications of heat-pumps in drying processes", Drying Technology, 12(4), pp. 889-901.

Sun Z.F.; Carrington, C.G., 1999, "Dynamic Modelling of a Dehumidifier Wood Drying Kiln", Drying Technology, 17(4-5), pp. 711-729.

Tai, K.W.; Devotta, S.; Watson, F.A.; Holland, F.A., 1982, "The potential for heat pumps in drying and dehumidification systems- III: An experimental assessment of the heat pump characteristics of a heat pump dehumidification system using R114", International Journal of Energy Research, 6(4), 333-340.

Tai, K.W.; Zylla, R.; Devotta, S.; Diggory, P.J.; Watson, F.A.; Holland, F.A., 1982, "The potential for heat pumps in drying and dehumidification systems- II: An experimental assessment of the heat pump characteristics of a heat pump dehumidification system using R114", International Journal of Energy Research, 6(4), pp. 323-331.

Toal, B.R.; Morgan, R.; McMullan, J.T., 1988, "Experimental Studies of Low-temperature Drying by Dehumidification. 1- Apparatus and Theory", International Journal of Energy Research, 12(2), pp. 299-314.

Toal, B.R.; Morgan, R.; McMullan, J.T., 1988, "Experimental Studies of Low-Temperature Drying by Dehumidification. 2-Experimental", International Journal of Energy Research, 12(2), pp. 315-344.

Zylla, R.; Abbas, S.P.; Tai, K.W.; Devotta, S.; Watson, F.A; Holland, F.A., 1982, "The potential for heat pumps in drying and dehumidification systems - I: Theoretical considerations", International Journal of Energy Research, 6(4), pp. 305-322. 